\title{
Diagnosing of automotive alternators on thermal state
}

\author{
Andrey Puzakov ${ }^{1, *}$ \\ ${ }^{1}$ Orenburg State University, Pobedy avenue, 13, Orenburg, Russian Federation
}

\begin{abstract}
Since automotive alternators serve as the primary sources of power onboard of vehicles, the online diagnostics of technical conditions thereof is a relevant task. An advantage of temperature as a diagnostic parameter is sensitivity to most faults at the early stage of their development. Physical modeling of faults (stator one-line open fault, stator turn-to-turn short circuit, stator winding phase-to-phase short circuit, circuit opening and short circuit of rectifier diodes) has been done by forced increase (decrease) of electrical resistance between alternator elements. In order to measure alternator temperature, it has been brought to steady thermal state within 20 minutes. It has been found that the alternator temperature in case of faults can increase the rated temperature by $10-30{ }^{\circ} \mathrm{C}$ even when the alternator operates without load. An algorithm has been developed to find alternator faults by evaluating the thermal state thereof, which can become a basis of an onboard automatic online diagnosing system of an automotive alternator.
\end{abstract}

\section{Introduction}

A modern automotive alternator is a reliable device that requires almost no maintenance during operation (except for replacement of brushes) [1].

Despite of that, automotive alternators unavoidably have faults, some of which cause the transportation process to stop. Since a vehicle is equipped with multiple electrical and electronic systems, including safety systems, the probability of road accidents rises (for example, alternator failure results in tripping of the electric assist).

Given that the remaining life of electrical machines in accordance with depends on their thermal state, it is required to specify the thermal state of operable and faulty alternators. Using temperature as a diagnostics parameter will result in reduced time for finding the nature of failure, faster troubleshooting and, respectively, shorter downtime of vehicles during repair.

Figure 1 shows interrelation between individual failures of alternators and the changes in their thermal state.

In case of constant loads and speed rates, the alternator technical condition can characterize the principles of temperature changes during startup.

\footnotetext{
*Corresponding author: and-rew78@yandex.ru
} 


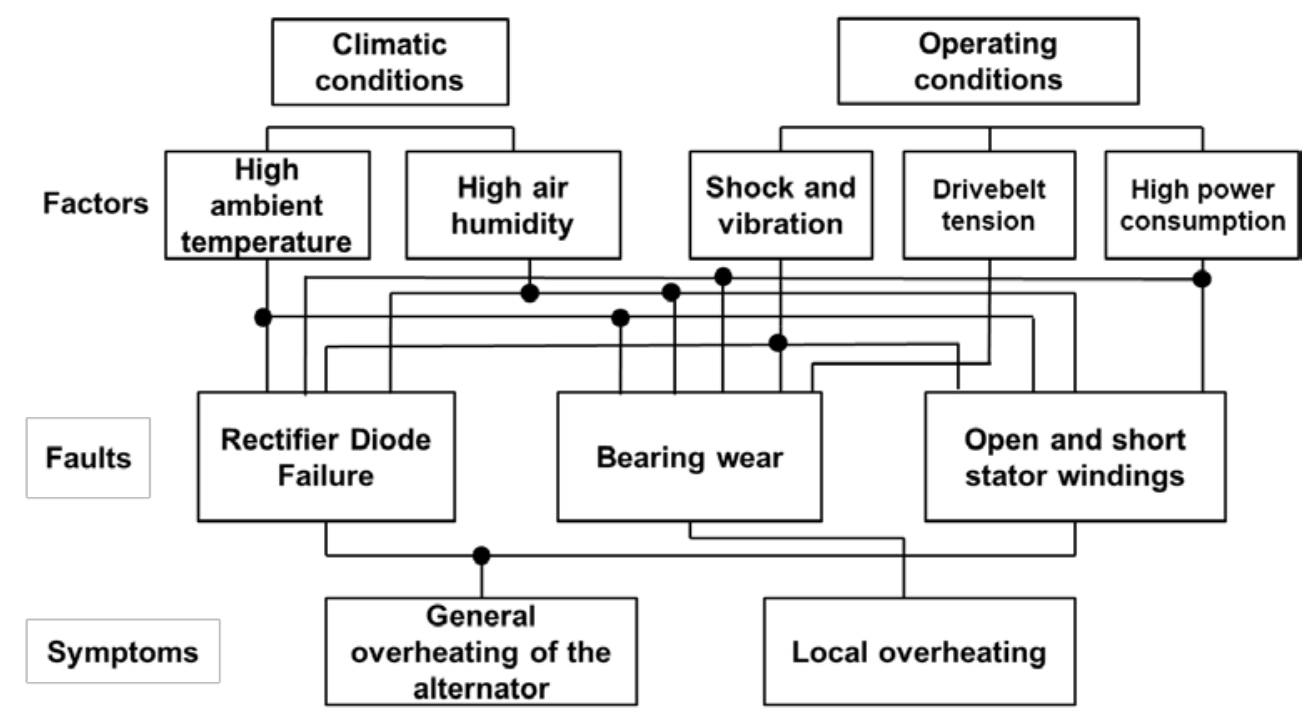

Fig. 1. Interrelation between alternator faults and changes in their thermal state

The alternator housing heating temperature as a diagnostic parameter has two specific features: some type of failures causes the alternator housing temperature to rise; heating rate of response of metallic parts, housings and supports prevents from using this parameter to determine sudden failures and developing defects [2].

\section{Nature of changes in alternator thermal state}

In case of constant loads and speed rates, the alternator technical condition may characterize principles of temperature changes during startup. There are three-time phases (Figure 2) corresponding to disordered heating $A$, regular thermal state $B$ and steady thermal state $C$.

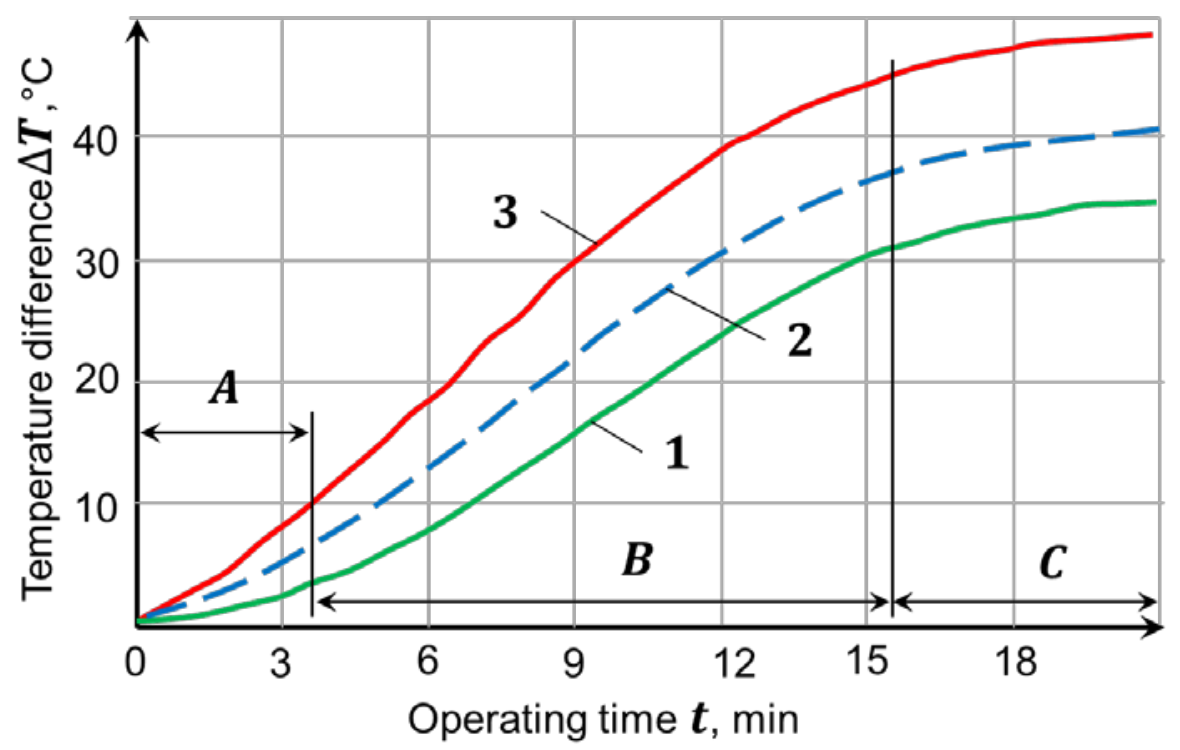

Fig. 2. Nature of changes in alternator thermal state 
The phase of disordered heating is of random nature during startup, so it is not used to get information on technical condition. Steady state (when thermal balance is reached) is noninformative since the significant time and precise temperature control is required for the alternator to reach this state: it is frequent that the temperature difference in this state is insignificant in operative and faulty alternators. In this connection, information is acquired at the second stage of heating when the temperate rises to a specific boundary value [3], [4], [5], [6], [7], [8], [9], [10], [11], [12], [13], [14], [15].

The intensity of temperature rise in a faulty alternator will be higher than in an operative one. To get information about the intensity of temperature rise, two consecutive measurements are enough: at the initial section of the thermal state phase and after some time. The permitted alternator heating intensity when entering the steady thermal state is + $0.5^{\circ} \mathrm{C} / \mathrm{min}$.

During an experiment in a special stand [16], the automotive alternator housing (14V, 90A) was fitted with a solid-state temperature sensor, with the temperature indicator mounted on the stand instrument panel (Figure 3).

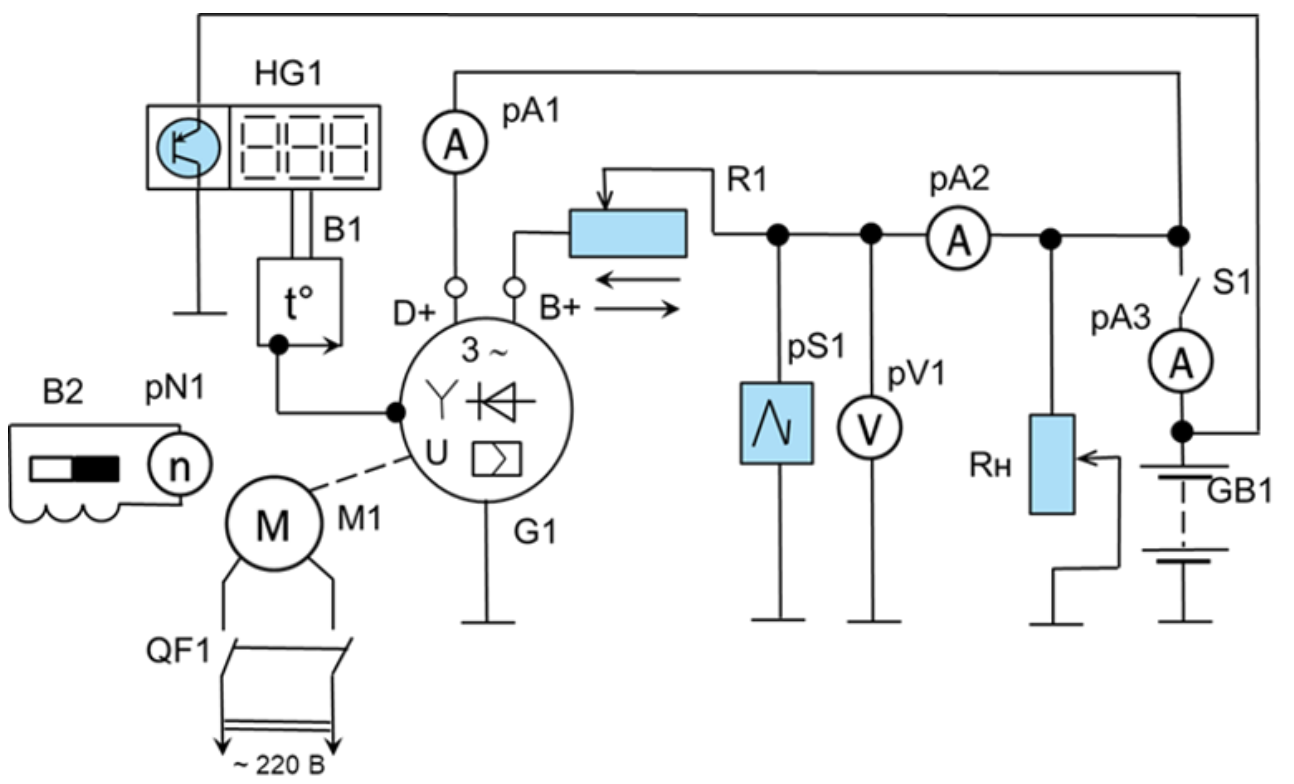

B1 - alternator temperature sensor, B2 - rotation speed sensor; G1 - tested alternator, GB1 - battery, HG1 - temperature indicator, M1 - electrical motor, QF1 - circuit breaker, pA1 - pA2 - amperemeter, pV1 - voltmeter, pN1 - tachometer, pS1 - oscilloscope, R1 - laboratory rheostat, S1 - battery switch

Fig. 3. Nature of changes in alternator thermal state

The experiment was carried out as follows. Fixed power of loads and rotation frequency were set at first. These factors define the scope of thermal energy emitted by the alternator and its removal efficiency, respectively, and jointly define the alternator thermal state. For each of the fixed values, the final heating temperature was measured in steady state. When the temperature changed by 1 degree, the time since experiment start was recorded, this allowed finding the alternator rate of heating.

Figure 4 represents temperature dependence from the heating time.

The curve has the following areas: regular thermal state $t_{1}$ that shows normal temperature rise; heat accumulation $t_{2}$ that shows fast temperature rise; natural cooling $t_{3}$. The first two areas are characterized by different rate of heating since at the first stage the alternator operates in self-ventilation mode, and at the second stage the internal fan does not operate. 


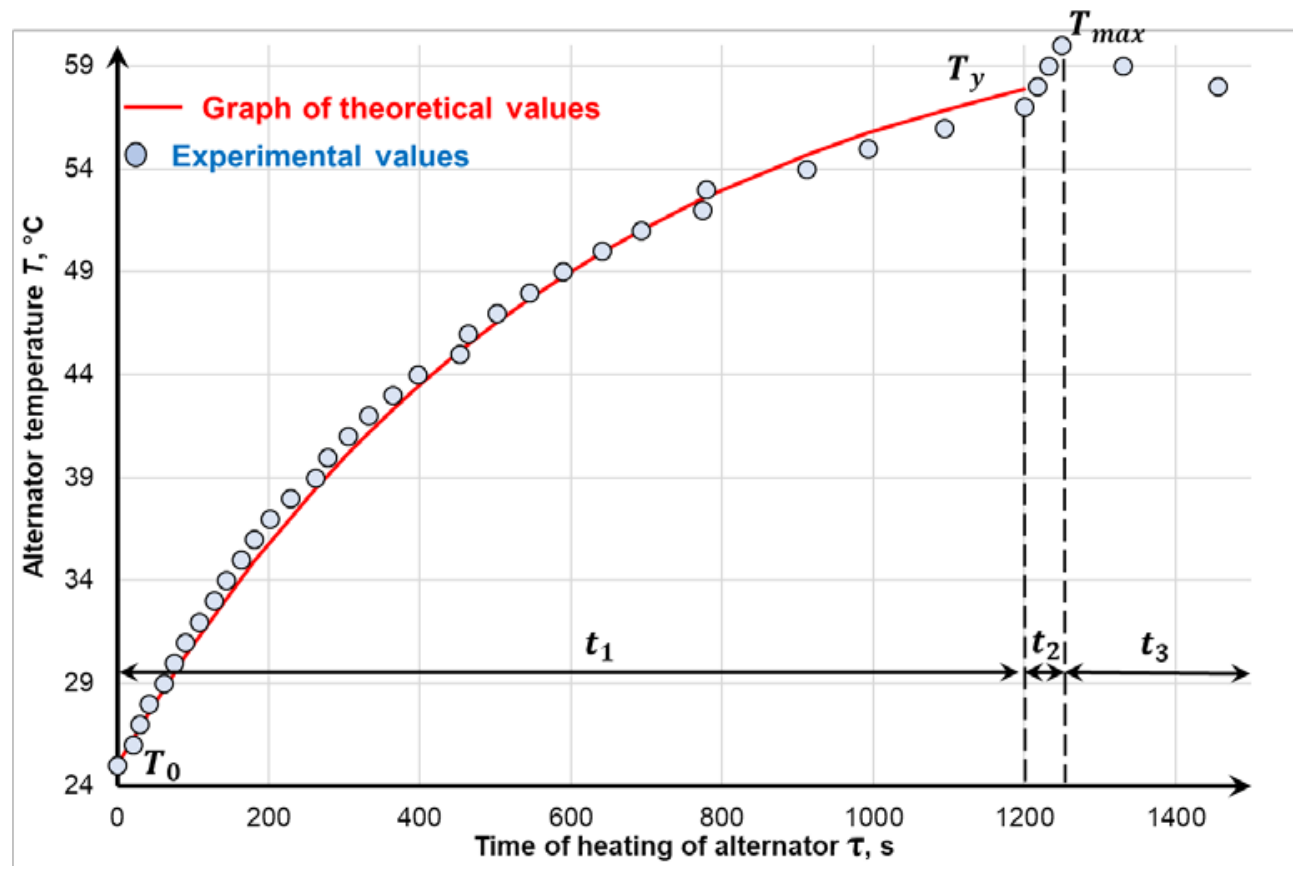

Fig. 4. Temperature dependence from alternator heating time

The heating rate is described by the following formula:

$$
m=\Psi \frac{\alpha \cdot F}{C \cdot M}
$$

where $m$ is the heating rate, $1 / \mathrm{s}$;

$\Psi$ is the temperature distribution irregularity coefficient;

$\alpha$ is the coefficient of heat output from the alternator surface, $\mathrm{W} / \mathrm{m}^{2} \cdot \mathrm{K}$;

$F$ is the alternator surface area, $\mathrm{m}^{2}$;

$C$ is the alternator heat capacity, $\mathrm{J} / \mathrm{kg} \cdot \mathrm{K}$;

$M$ is the alternator weight, $\mathrm{kg}$.

Point $T_{\mathrm{y}}$ corresponds to the maximum heating in case of alternator normal operation. It was recorded during further experiments.

The alternator heating is described by exponential dependency

$$
T=T_{0} \cdot\left(1+\alpha \cdot\left(1-e^{-\tau / t}\right)\right)
$$

where $T$ is the current temperature, ${ }^{\circ} \mathrm{C}$;

$T_{0}$ is the initial temperature, ${ }^{\circ} \mathrm{C}$;

$\alpha$ is the coefficient depending on the alternator operability;

$\tau$ is the time since alternator operation start, s;

$t$ is the total time of alternator operation, s. 


\section{Experiment results}

For physical modeling of faults, resistances made of nickel-chromium spiral are connected to alternator elements in series and parallel $[17,18]$.

Physical modeling of a fault in the stator winding is done by a special pin located on the outside of the stator winding. To this end, the alternator cover has a cut and some ribs are removed to ensure access to the winding.

To model the transient resistance of the insulation layer in the fault point, this pin is closed through adjustable active resistance. This allows adjusting the current in the shorted circuit and getting various degrees of studied damages that are created by changing current in the shorted circuit.

Diode faults include internal circuit opening (resistance tends to infinity) and short circuit (resistance tends to zero), so for physical modeling of these faults, a rheostat is connected to the diode in series (parallel) whose resistance can be changed to get a number of intermediate values apart from the above boundary ones [19].

Evaluation results of heat state acquired for an operative alternator and the number of the above faults are given in Figure 4.



Fig. 5. Temperature dependence from alternator technical condition

The dependencies given in Figure 4 show that faults promote alternator temperature rise, with the overtemperature being defined by the nature of the fault. The highest recorded overheating corresponds to the stator phase turn-to-turn short circuit, and the lowest one to the rectifier diode opening. This is agreed with the relevance of these defects since in case of diode opening the alternator is still operating but the developed voltage is greatly reduced, which will result in under-charging of the vehicle battery. The stator phase turn-to-turn short circuit is accompanied by a characteristic sound; the alternator output voltage is so low that the loads switch to power supply from the battery. 
In this manner, it has been found that occurrence and development of electrical faults is accompanied by the alternator temperature rise, and the fault can be identified by the magnitude of overheating. These results may become a basis for an automatic testing system of the alternator technical condition.

\section{Algorithm development}

The experimental data was used to develop an algorithm to determine alternator failures. The reference data for this algorithm is Table 1 containing values of surface overtemperature of an operative alternator.

Sensors are used to measure alternator surface temperature, ambient air temperature, crank-shaft rotation speed, loads current, onboard voltage.

This data is used to calculate loads powers, alternator steady overheating, difference between real and tabular overtemperature.

A specific value of deviation of real overtemperature from the tabular one will correspond to each alternator failure. By comparing these values, we can understand whether the alternator is operative, and if not - what element is faulty.

Table 1. Operative alternator surface overtemperature

\begin{tabular}{|c|l|l|l|l|l|l|l|l|}
\hline & \multicolumn{7}{|c|}{ Crank-shaft rotation speed, rpm } \\
\cline { 2 - 9 } & & $\mathbf{1 0 0 0}$ & $\mathbf{1 5 0 0}$ & $\mathbf{2 0 0 0}$ & $\mathbf{2 5 0 0}$ & $\mathbf{3 0 0 0}$ & $\mathbf{3 5 0 0}$ & $\mathbf{4 0 0 0}$ \\
\cline { 2 - 9 } & $\mathbf{1 0}$ & 24.6 & 24.1 & 23.8 & 23.6 & 23.5 & 23.4 & 23.2 \\
\cline { 2 - 9 } & $\mathbf{2 0}$ & 29.4 & 27.2 & 26.2 & 25.5 & 25.1 & 24.6 & 24.3 \\
\cline { 2 - 9 } & $\mathbf{3 0}$ & 37.4 & 32.6 & 30.2 & 28.7 & 27.8 & 27.0 & 26.3 \\
\cline { 2 - 9 } & $\mathbf{4 0}$ & 48.6 & 40.1 & 35.8 & 33.2 & 31.5 & 30.2 & 29.1 \\
\cline { 2 - 9 } & $\mathbf{5 0}$ & 63.0 & 49.7 & 43.0 & 39.0 & 36.3 & 34.1 & 32.2 \\
\cline { 2 - 9 } & $\mathbf{6 0}$ & 80.6 & 61.4 & 51.8 & 46.0 & 42.2 & 39.7 & 36.1 \\
\cline { 2 - 9 } & $\mathbf{7 0}$ & 101.4 & 75.3 & 62.2 & 54.4 & 49.1 & 44.5 & 40.2 \\
\cline { 2 - 9 } & $\mathbf{8 0}$ & 124.5 & 91.3 & 74.2 & 63.9 & 57.1 & 53.6 & 48.3 \\
\hline
\end{tabular}

Figure 6 represents a structural diagram of an automatic system for evaluation of the alternator heat state that shows its primary elements necessary for algorithm operation and interrelation between them.

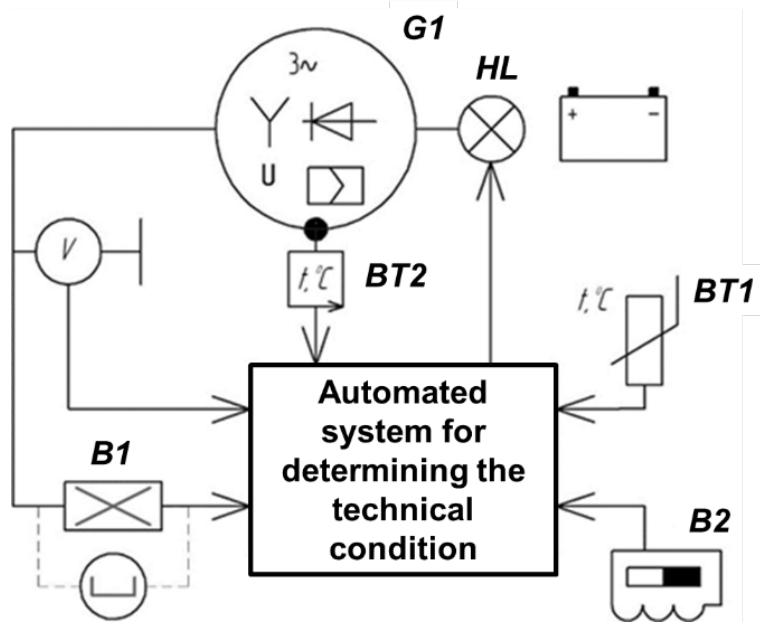

BT1 - air temperature sensor; BT2 - alternator surface temperature sensor; B1 - current sensor; B2 - crank-shaft position sensor; G1 automotive alternator; $\mathrm{V}$ - mains voltage sensor; HL - signal lamp on the instrument panel

Fig. 6. Structural diagram of an automatic system for evaluation of the alternator heat state 
Figure 7 represents an algorithm of finding alternator faults. It shows all data and operations that help acquiring information about the assembly condition.


Fig. 7. Algorithm of finding alternator faults

The acquired results can become a basis for an onboard alternator condition testing automatic system that will increase the technical readiness in emergency service vehicles and reduce repair downtimes.

\section{Conclusions}

Since automotive alternators serve as the primary sources of power onboard of vehicles, the online diagnostics of technical conditions thereof is a relevant task. An advantage of temperature as a diagnostic parameter is sensitivity to most faults at the early stage of their development.

Physical modeling of faults (stator one-line open fault, stator turn-to-turn short circuit, stator winding phase-to-phase short circuit, circuit opening and short circuit of rectifier diodes) has been done by forced increase (decrease) of electrical resistance between alternator elements. In order to measure alternator temperature, it has been brought to steady thermal state within 20 minutes. It has been found that the alternator temperature in case of faults can increase the rated temperature by $10-30{ }^{\circ} \mathrm{C}$ even when the alternator operates without load. 
An algorithm has been developed to find alternator faults by evaluating the thermal state thereof, which can become a basis of an onboard automatic online diagnosing system of an automotive alternator.

\section{References}

1. A.G. Sergeev, V.E. Yutt, Diagnostics of electric equipment of cars (Moscow, Transport, 1987)

2. M. Mürken, D. Kübel, A. Kurz, A. Thanheiser, P. Gratzfeld, Conference on Electrical Systems for Aircraft, Railway, Ship Propulsion and Road Vehicles. Notthingham, 1-6. (2018)

3. M. Bradfield, http://www.electronics- cooling.com/2002/05/ thermal-designchallenges-in-automotive-alternatorpower-electronics/ [Apr. 11, 2011]. (2002)

4. S. Brisset, M. Hecquet, P. Brochet, COMPEL - The international journal for computation and mathematics in electrical and electronic engineering, Vol. 20 No. 1, 205-215 (2001)

5. S. Cheng, T.G. Habetler, 8th IEEE Symposium on Diagnostics for Electrical Machines, Power Electronics \& Drives, Bologna, 606-611. (2011)

6. M.-K. Chen, International Conference on Electrical Machines and Systems (ICEMS), Seoul, 1041-1045. (2007)

7. A. D’Annibale, A. Di Ilio, M. Trozzi, L. Bonaventura, Procedia CIRP, Vol. 38, 143-146. (2015)

8. M. Dziubiński, R. Longwic, Badania Symulacyjne w Technice Samochodowej Materiały na V Międzynarodową KonferencjęAt: Kazimierz Dolny. 79-85. (1995)

9. J. Kim, J. Hong, J. Lee, S. Park, IEEE International Magnetics Conference (INTERMAG), Beijing, 1-1. (2015)

10. O. Maloberti, A. Gimeno, A. Ospina, G. Friedrich, K. El-Kadri-Benkara, L. Charbonnier, XXth International Conference on Electrical Machines, Marseille, 18881892. (2012)

11. O. Maloberti, A. Gimeno, A. Ospina, G. Friedrich, K. El-Kadri-Benkara, L. Charbonnier, Industry Applications, IEEE Transactions on. 50. 279-287 (2014)

12. O. Meksi, A.V. Ospina, Symposium de Génie Électrique 2014, Jul 2014, Cachan, France. (2011)

13. S. Styla, K. Wróbel, A. Boguta, Teka. Commission of motorization and energetics in agriculture, Vol. 13, No. 1, 185-190 (2013)

14. S. Tang, T.A. Keim, D.J. Perreault, In IEEE Transactions on Energy Conversion, vol. 20, no. 1, 25-36. (2005)

15. W. Zhu, K. Zhang, Y. Wang, Asia-Pacific Power and Energy Engineering Conference, Chengdu, 1-4. (2010)

16. M.I. Filatov, A.V. Puzakov, Ya.Yu. Osaulko, News of the Orenburg State Agrarian University. 1(69). 102-106. (2018)

17. A.V. Puzakov, Ya.Yu. Osaulko, Bulletin of the Moscow Automobile and Road State Technical University (MADI). 1(52). 16-23. (2018)

18. Ya.Yu. Osaulko, A.V. Puzakov, The world of transport and technological machines. 4(63). 20-27. (2018)

19. A.V. Puzakov, Ya.Yu. Osaulko, Electronics and electrical equipment of transport. 5. 59. (2018) 